\title{
Stop Motion como estratégia de ensino e aprendizagem para crianças, jovens e adultos
}

\author{
Sylvana Karla da Silva de Lemos Santos ${ }^{1}$, Cristiane Yukiko Kondo ${ }^{2}$ \\ ${ }^{1}$ Instituto Federal de Brasília (IFB) - Campus Brasília - DF - Brasil. \\ ${ }^{2}$ Instituto Federal do Espírito Santo (IFES) - Campus Vitória - ES - Brasil. \\ \{sylkarla, crikondo\}egmail.com
}

\begin{abstract}
The Stop Motion technique, because it is relatively simple and requires few resources, favors its use in the classroom. The aim of the study was to promote the interaction of users, aged between 8 and 11 years, with the tool and to observe the interest to plan future activities with other groups of students. The results obtained demonstrate that the application of digital technologies associated with the Stop Motion technique can promote the empowerment of the student, who moves from consumer to producer of audiovisual content, and serves as an alternative for the elaboration of teaching and learning strategies by educators. To continue, there is a workshop with middle and high school students.
\end{abstract}

Resumo. A técnica Stop Motion, por ser relativamente simples e exigir poucos recursos, favorece seu uso em sala de aula. $O$ estudo teve como objetivo promover a interação dos usuários, com idade entre 8 e 11 anos, com a ferramenta e observar o interesse para planejar atividades futuras com outros grupos de estudantes. Os resultados obtidos demonstram que a aplicação de tecnologias digitais associadas à técnica do Stop Motion pode promover o empoderamento do educando, que passa de consumidor a produtor de conteúdo audiovisual, e servir como alternativa para a elaboração de estratégias de ensino e aprendizagem por educadores. Para dar continuidade, está prevista uma oficina com estudantes de nível médio e superior.

\section{Introdução}

A crescente mudança no meio tecnológico, assim como a disseminação do uso de dispositivos móveis, cada vez mais disponível e presente no cotidiano dos alunos e das escolas, oferece diversas possibilidades de uso juntamente com o surgimento de novos aplicativos. A produção de conteúdo em forma de vídeos é uma dessas possibilidades, na qual os estudantes são sujeitos ativos na criação, desenvolvendo um aprendizado de forma significativa e proativa.

Ernst, Silveira e Lima [2014, p. 2] afirmam que "o processo de emancipação tecnológica faz parte do reconhecimento do sujeito como integrante da sociedade". Neste sentido, se o educador permite que seus estudantes tenham oportunidades para criar e compartilhar, inicia-se um processo de autonomia do sujeito na sociedade. 
VIII Congresso Brasileiro de Informática na Educação (CBIE 2019)

Anais do XXV Workshop de Informática na Escola (WIE 2019)

Este artigo consiste em apresentar a técnica Stop Motion como estratégia para auxiliar na produção de conteúdo por estudantes e educadores para que possa ser utilizado no processo de ensino e aprendizagem em ambiente escolar. Para tanto, tem como objetivo promover a interação dos usuários com a ferramenta e observar $\mathrm{o}$ interesse para planejar atividades futuras com grupos de estudantes de nível técnico e superior. Destaca-se a possibilidade de atendimento às necessidades específicas de um público considerado minoritário e propõe-se utilizar alguns recursos para satisfazer a demanda das pessoas com necessidades específicas. Pessoas com deficiência auditiva podem se beneficiar dos recursos visuais, inclusive imagens e legendas, dispostos nos vídeos criados por meio da técnica Stop Motion. De modo semelhante, as pessoas com deficiência visual podem ser atendidas por meio do recurso de audiodescrição [Campos, Damásio e Inácio 2015]. Ademais, pessoas disléxicas também podem ser motivadas pela característica visual da produção, auxiliando-as a memorizar conteúdos [Lucena, Cidrim e Madeiro 2017].

\section{Stop Motion}

A técnica Stop Motion surgiu em 1911, quando utilizada em um filme do francês Émile Cohl [Penteado 2011, p. 26]. Trata-se de uma forma de produção de animação audiovisual que atrai um público variado e que, em geral, pode demandar tempo para ser executada. Por isso, necessita de um bom planejamento, que começa com a delimitação de um tema, a produção de um roteiro também chamado de storyboard, da escolha dos objetos a serem manipulados, a gravação, a edição e a publicação.

$\mathrm{Na}$ prática, cada quadro é fotografado para montar uma cena. A mudança dos objetos em cada quadro caracteriza o movimento que dá origem à animação. Em tempos de dispositivos móveis, para a gravação de alguns segundos de vídeo é suficiente um smartphone com um aplicativo de captura e edição. Com essas ferramentas também é possível inserir áudio com a narração da cena. Um exemplo de aplicativo com versões gratuitas é o "Estúdio Stop Motion” [Microsoft 2019].

Ao trabalhar com recursos multimídia, cria-se uma oportunidade de explorar os multiletramentos do sujeito que está em formação [Paula, Paula e Henrique, 2017, p. 142], além de promover o uso de tecnologia com foco em um tema que está sendo desenvolvido na área do currículo comum ou na formação técnica e tecnológica.

\subsection{Produções com a técnica Stop Motion}

Comercialmente, exemplos bem-sucedidos do emprego da técnica Stop Motion podem ser encontrados no cinema (A Fuga das Galinhas, A Noiva Cadáver, Wallace e Gromit), em séries de televisão estrangeiras e nacionais (Pingu, Porto Papel) e em propagandas comerciais (Lavadora Consul, Bic, Trident) [Comunicart 2019]. Os materiais utilizados para produção do vídeo variam de acordo com a criatividade do idealizador, podendo ser usado papel, massinha de modelar, desenhos, objetos diversos, pessoas ou uma associação destes.

O uso da técnica Stop Motion permite estabelecer uma ligação entre teoria e prática para identificar a interdisciplinaridade existente nos diversos componentes a serem estudados. Como exemplo, a produção de um vídeo que tem o tema central "poluição do ar e doenças respiratórias" pode englobar conceitos da saúde ao abordar as 
VIII Congresso Brasileiro de Informática na Educação (CBIE 2019)

Anais do XXV Workshop de Informática na Escola (WIE 2019)

doenças provocadas pela poluição dos carros e das indústrias (Figura 1). Além disso, a temática pode promover hábitos de cuidados pessoais e coletivos, como a limpeza para evitar mofo e ácaro [Kondo et al. 2018].

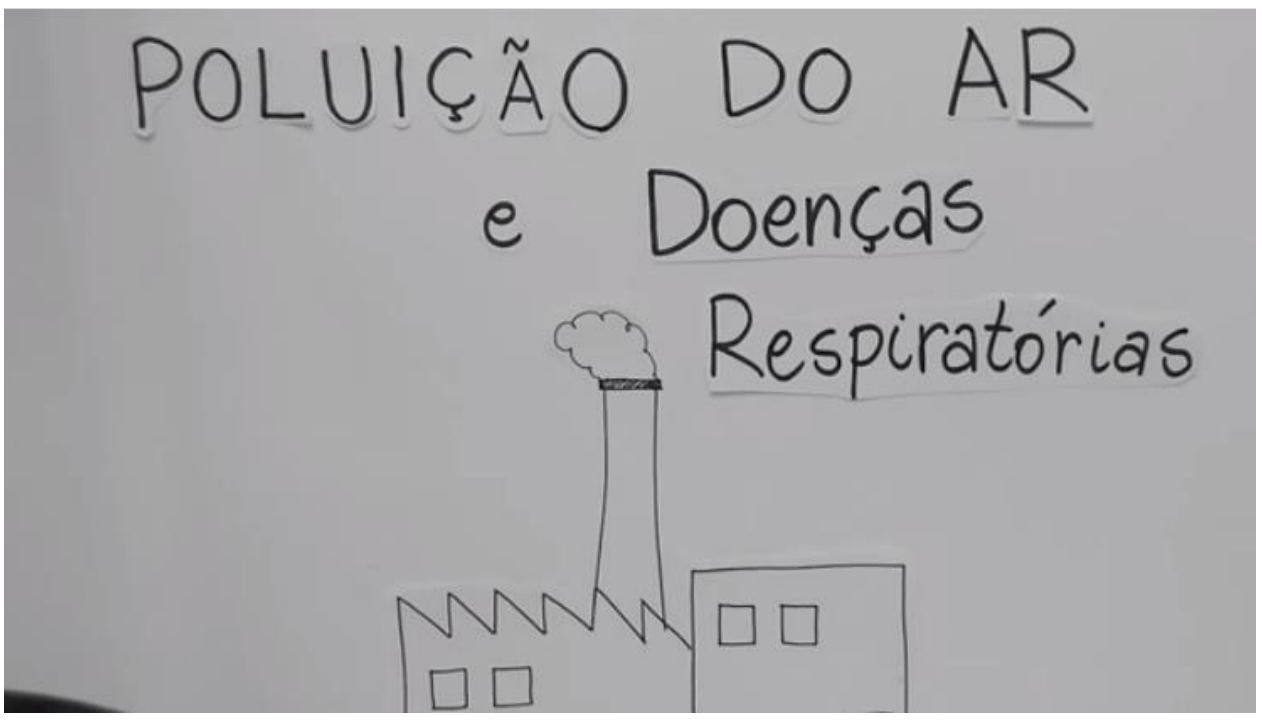

Figure 1. Produção de um vídeo com a técnica Stop Motion.

\section{Metodologia}

A pesquisa tem caráter qualitativo de cunho descritivo. Foram realizadas experiências por meio de observação que estimularam a produção de vídeos utilizando a técnica Stop Motion. O público da pesquisa envolveu quatro crianças com idades entre 8 e 11 anos em ambiente não formal de ensino, nos meses de Maio e Junho de 2018, nas cidades brasileiras de Vitória, no Espírito Santo, e Brasília, no Distrito Federal.

Inicialmente, foram apresentados para este público infantil alguns vídeos produzidos com a técnica Stop Motion publicados no Youtube e no Instagram. Em seguida, foi exibido um projeto de demonstração com o aplicativo "Estúdio Stop Motion", instalado no smartphone de uma das pesquisadoras, no qual as crianças perceberam que a passagem da sequência de fotos produzia o efeito de movimento no vídeo. Após a exploração livre do aplicativo e do projeto de demonstração, foi oferecido auxílio no uso para a produção de dois vídeos por cada criança, que foram incentivadas a produzir vídeos em duplas e individualmente. Os temas surgiram por iniciativa das próprias crianças e foram seguidos de pequenas pesquisas, também de iniciativa individual ou em dupla, no Google Imagens. Para a produção dos personagens e do cenário, as crianças fizeram ilustrações e dobraduras em papel e utilizaram brinquedos. Por meio de registros fotográficos, as crianças ajustaram o tempo de exposição de algumas fotos no aplicativo, adicionaram áudio, exportaram o vídeo, publicaram no YouTube e Instagram, e compartilharam com amigos e familiares por meio do Whatsapp.

\section{Resultados e Discussão}

A produção de vídeos por meio da técnica Stop Motion permite abordar o uso das tecnologias digitais, voltada ao planejamento e organização da produção do conteúdo, 
além da busca por um determinado tema. Percebeu-se que o interesse demonstrado pelas crianças que participaram da primeira fase da pesquisa foi ocasionado pela praticidade de uso da técnica, considerando suas habilidades com o smartphone, bem como pela facilidade em manipular objetos de fácil alcance e que são parte da sua rotina de brincadeiras, como desenhos, dobraduras e brinquedos. Dessa forma, a compreensão do efeito que a captura de imagens sequenciais promove, dando origem a um vídeo, serviu como estímulo para a organização de ideias para criar novas experiências com a escolha e utilização de outros objetos. Como exemplo, destaca-se a possibilidade de explicitar o desenvolvimento de uma planta, desde a semente até a germinação, utilizando uma sequência de imagens desenhadas ou capturadas periodicamente in vivo, e que pode servir para esclarecer conceitos das ciências biológicas em turmas da educação infantil ao ensino fundamental e auxiliar a memorizar as fases de desenvolvimento da planta pela característica visual.

Neste sentido, a técnica, por ser relativamente simples e exigir poucos recursos (câmera fotográfica e aplicativo), se mostra cada vez mais disponível para os estudantes de idades e níveis de escolaridade diversos, incluindo aqueles em formação técnica. Além disso, possui grande potencial de desenvolver a criatividade e habilidades comunicativas; permite abordar o uso das tecnologias digitais em todas as etapas (pesquisa, planejamento, registro fotográfico, uso do aplicativo, publicação e divulgação); provoca a pesquisa sobre o conteúdo para a elaboração do roteiro e permite estimular a produção de conteúdo que obedeçam a critérios de acessibilidade para auxiliar diferentes necessidades, a exemplo das pessoas com deficiência auditiva e visual.

Do mesmo modo, destacamos a importância para o processo de empoderamento, no qual o estudante deixa de ser apenas um consumidor de produções audiovisuais disponibilizadas na web para ser também um produtor de conteúdo digital, protagonizando sua participação na sociedade.

A próxima etapa da pesquisa será a realização de oficinas voltadas aos estudantes do curso técnico integrado ao ensino médio e graduandos da licenciatura em um campus do Instituto Federal de Brasília, de modo a observar o comportamento deste público, composto de jovens e adultos, para avaliar o interesse pela utilização da técnica e a possível associação com as disciplinas dos cursos para o atendimento às diferentes necessidades.

\section{Referências}

Campos, M. B.; Damásio, J.; Inácio, T. (2015) mAbES: Avaliação de uso de uma aplicação móvel para usuários que são cegos. In Simpósio Brasileiro de Informática na Educação, SBIE, p. 927-936, 2015. Disponível em: <http://www.brie.org/pub/index.php/sbie/article/view/5392/3753 > Acesso em: 06 jun. 2019.

Comunicart. "Propagandas em Stop Motion", 21 jan. 2013. Disponível em: $<$ http://comunicart.blog.br/2013/01/propagandas-em-stop-motion/> Acesso em: 03 mai. 2019.

Ernst, P., Silveira, R. M. C. F., Lima, S. A. (2014) Educação e Cinema: uma experiência de emancipação com a prática do Stop Motion nas aulas de ciências. In Simpósio 
VIII Congresso Brasileiro de Informática na Educação (CBIE 2019)

Anais do XXV Workshop de Informática na Escola (WIE 2019)

Nacional de Ensino de Ciência e Tecnologia, SINECT, 2014, p. 1-8. Disponível em: $<$ http://www.sinect.com.br/2014/down.php?id=3068\&q=1> Acesso em: 04 mai. 2018.

Kondo, C. et al. Poluição do ar e doenças respiratórias. Vídeo. 27 abr. 2018. Disponível em: <https://www.youtube.com/watch?v=ZZb14k_ZHG8\&>. Acesso em: 07 mai. 2019.

Lucena, G. C.; Cidrim, L.; Madeiro, F. (2017) Um aplicativo para estimulação da memória visual em crianças disléxicas por meio do jogo de palavras cruzadas. In Simpósio Brasileiro de Informática na Educação, SBIE, 2017, p. 685-694. Disponível em: < http://www.br-ie.org/pub/index.php/sbie/article/view/7597 > Acesso em: 06 jun. 2019.

Microsoft. Stop Motion Studio. Disponível em: $<$ https://www.microsoft.com/ptbr/p/stop-motion-studio/9wzdncrdk52q> Acesso em: 03 mai. 2019.

Paula, J. L., Paula, J. L., Henrique, A. L. S. (2017) O Uso do Stop-Motion como Prática Pedagógica no Ensino de Geografia no Contexto do EMI. Holos, Ano 33, v. 03. p. 141-149.

Disponível

em: $<$ http://www2.ifrn.edu.br/ojs/index.php/HOLOS/article/view/5774> Acesso em: 05 jun. 2019.

Penteado, A. L. O. (2011) "Cinema de Animação: uma proposta de trabalho para o ensino fundamental”, 54 f., Monografia (Graduação em Ensino das Artes Visuais) Faculdade de Ciências Humanas, Letras e Arte da Universidade Tuiuti do Paraná. 